\title{
Ring closing metathesis in protic media by means of a neutral and polar ruthenium benzylidene complex
}

\author{
Thomas Rölle*a,b and Robert H. Grubbs ${ }^{a}$ \\ a California Institute of Technology, The Arnold and Mabel Beckman Laboratory of Chemical Synthesis, \\ Pasadena, CA 91125, USA \\ ${ }^{b}$ Bayer AG, Central Research, D-51368,Leverkusen, Germany.E-mail: thomas.roelle.tr@bayer-ag.de
}

Received (in Cambridge, UK) 25th February 2002, Accepted 28th March 2002

First published as an Advance Article on the web 15th April 2002

The ring closing olefine metathesis in protic solvents using a new ruthenium benzylidene complex is described.

Ring closing metathesis (RCM) has been established as a powerful and efficient synthetic method for carbon-carbon bond formation leading to carbo- and heterocycles. ${ }^{1}$ Many useful transformations have been reported for industrial applications as well as for the synthesis of complex molecules. Today, there are several examples of early transition metal complexes reported that are active catalysts for RCM, most of them tend to be very sensitive towards impurities, oxygen, water or functional groups, however. ${ }^{2,3}$ It was also shown that not only were many functional groups tolerated but that RCM could be achieved in methanol and water using suitable substrates., ${ }^{4,5}$ Moreover, ring closing metathesis has been succesfully carried out in ionic liquids or supercritical $\mathrm{CO}_{2}{ }^{6}$ Nevertheless, metathesis active ruthenium alkylidenes, at least those bearing phosphine ligands, require sterically bulky and electron rich phosphine ligands (such as $\mathrm{PCy}_{3}$ ) to provide and maintain favorable catalytic activity. ${ }^{7}$ To enhance the solubility of phosphine stabilized metal complexes in polar solvents in general, polarity is carried most likely by the phosphine backbone. ${ }^{8}$

We report here the preparation of a modified ruthenium benzylidene complex $\mathbf{2}$ for ring closing metathesis by using a new class of neutral, electron-rich and polar phosphine represented by 1 .

Formally replacing one methylene group of the cyclohexyl rings of the $\mathrm{PCy}_{3}$ ligand by a polar functionality, e.g. a sulfone moiety, will therefore generate a phosphine 1 with significant enhanced polarity when compared to $\mathrm{PCy}_{3}$ (Scheme 1). Herein, the 4-position was selected for the isoelectronic replacement far apart from the metal ion because we expected the most dramatic influence on the solubilty while only minor changes in the coordination chemistry should take place, since the rather small change in the ligand backbone should not diminish the required electron donor capabilities of the phosphorous as it was observed in charged phosphines that were reported earlier. ${ }^{4}$ With 1 having presumably similar electronic properties to $\mathrm{PCy}_{3}$, we attempted to generate a derived ruthenium benzylidene $\mathbf{2}$.

For the latter purpose, alcohol $\mathbf{5}$ appeared to be an attractive precursor that might be functionalized by further reaction to yield the phosphine $\mathbf{1}$. The synthesis of $\mathbf{5}$ had been described earlier, although, in our hands following this synthetic pathway yields were found to be very low. ${ }^{9}$ Instead, the easily prepared
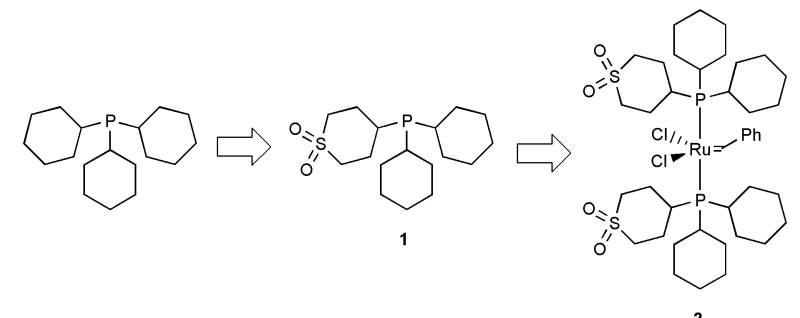

Scheme 1 tetrahydrothiopyran $3^{9 a}$ was first reduced with $\mathrm{NaBH}_{4}$ to yield the alcohol 4 in $96 \%$ yield and subsequently oxidized using 2 equivalents of potassium periodate yielding the sulfone $\mathbf{5}$ in 98\% (Scheme 2).

In the following step, we attempted to activate $\mathbf{5}$ for a nucleophilic coupling with the deprotonated (dicyclohexylphosphino)borane. After treatment of alcohol 5 with 1.1 equivalents trifluoromethanesulfonic anhydride in the presence of pyridine in dichloromethane, ${ }^{10}$ the triflate $\mathbf{6}$ was formed in about $90 \%$ yield. Since $\mathbf{6}$ had a very strong tendency to undergo side reactions-especially an elimination reaction leading to unsaturated sulfones - the triflate was used only in situ. After carefully optimizing the reaction conditions, we found that 6 alkylates the deprotonated dicyclohexylphosphine in THF solution at low temperatures $\left(-78^{\circ} \mathrm{C}\right)$. The phosphine 7 , which forms a colorless crystalline solid, was then purified by column chromatography over silica and isolated in a moderate yield of $56 \%$. To remove the borane protecting group, the phosphine was released after heating in morpholine at $110^{\circ} \mathrm{C}$ for $2 \mathrm{~h}$ as monitored by ${ }^{31} \mathrm{P}$ NMR. The morpholine was subsequently removed under reduced pressure and the remaining solid mixture of the morpholino-borane adduct and 7 was heated to $60{ }^{\circ} \mathrm{C}$ under high vacuum for several hours to quantitatively remove the morpholino-borane. Phosphine 7 slowly oxidizes upon exposure to air or in non-degassed solvents. As expected, 7 is completely soluble in dichloromethane, benzene, methanol, and water-methanol $3: 1(\mathrm{v} / \mathrm{v})$.

Taking advantage of the well-established catalyst precursor $\mathrm{Cl}_{2} \mathrm{Ru}(=\mathrm{CHPh})\left(\mathrm{PPh}_{3}\right)_{2}$, the ligand exchange reaction with a more basic and stronger donor phosphine generally proceeds quickly and opens access to many versatile substitution patterns. It has to be kept in mind that triphenylphosphine must be removed quantitatively from the newly formed ruthenium benzylidene to achieve optimal catalytic activity.

The ruthenium benzylidene 2 was prepared by phosphine exchange reaction of $\mathrm{Cl}_{2} \mathrm{Ru}(=\mathrm{CHPh})\left(\mathrm{PPh}_{3}\right)_{2}$ with 7 in dichloromethane at room temperature. ${ }^{3 b}$ Following this procedure, no side products were detectable by means of ${ }^{1} \mathrm{H},{ }^{13} \mathrm{C}$, and ${ }^{31} \mathrm{P}$ NMR spectroscopy (Scheme 3).

The resulting complex 2 was purified by washing the crude reaction product several times with $n$-pentane to remove the free $\mathrm{PPh}_{3}$. Compound 2 was isolated in $73 \%$ yield as a dark red, microcrystalline solid. The ruthenium benzylidene $\mathbf{2}$ is soluble in benzene, dichloromethane, methanol, and methanol-water $3: 1(\mathrm{v} / \mathrm{v})$, respectively. Characteristic and representative NMR resonances for 2 were found at $\delta 20.08 \mathrm{ppm}\left({ }^{1} \mathrm{H}\right.$ NMR) and $\delta$

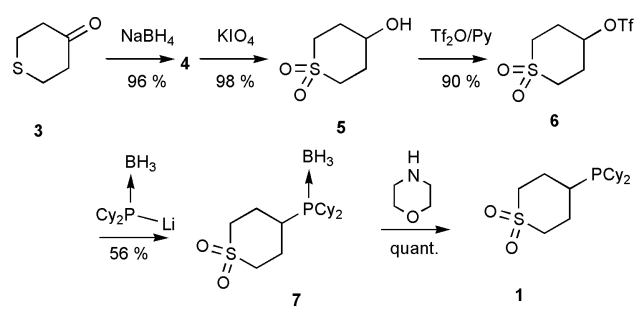

Scheme 2 

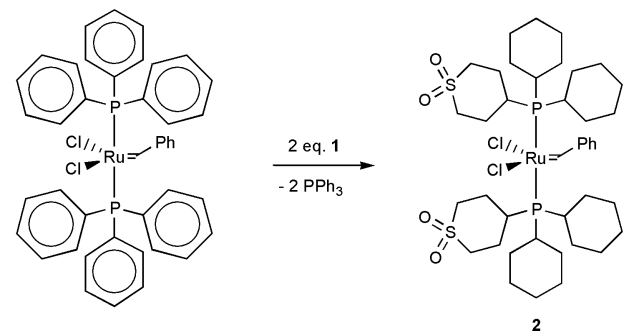

Scheme 3

$37.0 \mathrm{ppm}$ ( ${ }^{31} \mathrm{P}$ NMR). In methanol or benzene solution, $\mathbf{2}$ was found to be stable at room temperature for several days, but at $50{ }^{\circ} \mathrm{C}$, decomposition is observed after $24 \mathrm{~h}$.

To explore the RCM activity of 2, the diethyl allyl(cinnamyl)malonate 8 was treated with $3 \mathrm{~mol} \%$ of 2 in methanol at $40{ }^{\circ} \mathrm{C}$ (Scheme 4). The 5-membered cyclopentane $\mathbf{1 0}$ is formed almost quantitatively after $12 \mathrm{~h}$ at $40{ }^{\circ} \mathrm{C}\left({ }^{1} \mathrm{H}\right.$ NMR; gas chromatography). During RCM of 8, 2 is the active catalytic species because it is regenerated in each turnover. ${ }^{4} a$ It should be mentioned that RCM of $\mathbf{8}$ can be carried out in aqueous methanol at $40{ }^{\circ} \mathrm{C}$, benzene or dichloromethane at $25^{\circ} \mathrm{C}$, too. The yield is slightly decreased in aqueous methanol due to a faster decomposition of $\mathbf{2}$. The diethyl diallylmalonate $\mathbf{9}$ quantitatively undergoes RCM using $\mathbf{2}$ as catalyst to form $\mathbf{1 0}$ under the standard conditions (Table 1 , entry 5 ).

We therefore conclude that $\mathbf{2}$ is an active catalyst for the RCM reaction of suitable substrates in a broad range of organic solvents.

While the commercially available ruthenium benzylidenes are found to be almost insoluble in polar solvents and the reported cationic complexes are only soluble in methanol and water, $\mathbf{2}$ offers the benefit of being soluble in almost any solvent and still being an active catalyst for the RCM.

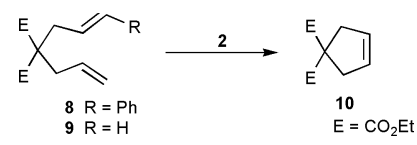

Scheme 4

Table 1 Ring closing metathesis of dienes $\mathbf{8}$ and $\mathbf{9}^{a}$

\begin{tabular}{|c|c|c|c|c|c|}
\hline Entry & Substrate & Solvent & Temperature $/{ }^{\circ} \mathrm{C}$ & Time/h & Yield \\
\hline 1 & 8 & $\mathrm{MeOH}$ & 40 & 12 & $98 \%$ \\
\hline 2 & 8 & $\mathrm{MeOH}-\mathrm{H}_{2} \mathrm{O}(3: 1)$ & 40 & 12 & $78 \%$ \\
\hline 3 & 8 & $\mathrm{CH}_{2} \mathrm{Cl}_{2}$ & 25 & 4 & Quant. \\
\hline 4 & 8 & Benzene & 25 & 4 & Quant. \\
\hline 5 & 9 & $\mathrm{CH}_{2} \mathrm{Cl}_{2}$ & 25 & 4 & Quant. \\
\hline
\end{tabular}

This work was supported by the National Science Foundation (Grant No. 55202), T. R. is grateful to the Alexander von Humboldt Foundation for a Feodor Lynen fellowship.

\section{Notes and references}

1 (a) R. H. Grubbs and S. Chang, Tetrahedron, 1998, 54, 4413-4450; (b) M. L. Randall and M. L. Snapper, J. Mol. Cat. A: Chem., 1998, 133, 29-40; (c) M. Schuster and S. Blechert, Angew. Chem., 1997, 109, 2124-2145 (Angew. Chem., Int. Ed. Engl., 1997, 36, 2037-2056); (d) A. Fürstner, Angew. Chem., 2000, 112, 3140-3172 (Angew. Chem., Int Ed., 2000, 39, 3012); (e) T. M. Trnka and R. H. Grubbs, Acc. Chem Res., 2001, 34, 18-29.

2 (a) G. C. Fu and R. H. Grubbs, J. Am. Chem. Soc., 1992, 114 5426-5427; (b) W. A. Nugent, J. Feldman and J. C. Calabrese, J. Am. Chem. Soc., 1995, 117, 8992-8998; (c) M. Leconte, S. Pagano, A Mutch, F. Lefebvre and J. M. Basset, Bull. Soc. Chim. Fr., 1995, 132, 1069-1071.

3 (a) P. Schwab, M. B. France, J. W. Ziller and R. H. Grubbs, Angew. Chem., Int. Ed. Engl., 1995, 34, 2039-2041; (b) P. Schwab, R. H. Grubbs and J. W. Ziller, J. Am. Chem. Soc., 1996, 118, 100-110.

4 (a) B. Mohr, D. M. Lynn and R. H. Grubbs, Organometallics, 1996, 15, 4317-4325; (b) D. M. Lynn, B. Mohr and R. H. Grubbs, J. Am. Chem. Soc., 1998, 120, 1627-1628; (c) T. A. Kirkland, D. M. Lynn and R. H. Grubbs, J. Org. Chem., 1998, 63, 9904-9909; (d) D. M. Lynn, B. Mohr, R. H. Grubbs, L. M. Henling and M. W. Day, J. Am. Chem. Soc., 2000, 122, 6601-6609; (e) M. Saoud, A. Romerosa and M. Peruzzini, Organometallics, 2000, 19, 4005-4007; $(f)$ D. M. Lynn and R. H. Grubbs, J. Am. Chem. Soc., 2001, 123, 3187-3193.

5 (a) H. E. Blackwell and R. H. Grubbs, Angew. Chem., 1998, 110, 3469-3472 (Angew. Chem., Int. Ed. Engl., 1998, 37, 3281-3284); (b) S. J. Miller, H. E. Blackwell and R. H. Grubbs, J. Am. Chem. Soc., 1996, 118, 9606-9614.

6 (a) A. Fürstner, M. Liebl, C. W. Lehmann, M. Picquet, R. Kunz, C. Bruneau, D. Touchard and P. H. Dixneuf, Chem. Eur. J., 2000, 6, 1847-1857; (b) M. Picquet, D. Touchard and P. H. Dixneuf, New. J. Chem., 1999, 23, 141-143; (c) R. C. Buijsman, E. van Vuuren and J. G. Sterrenburg, Org. Lett., 2001, 3, 3785-3787; (d) A. Fürstner, L. Ackermann, K. Beck, H. Hori, D. Koch, K. Langemann, M. Liebl, C. Six and W. Leitner, J. Am. Chem. Soc., 2001, 123, 9000-9006; (e) D. Sémeril, H. Olivier-Bourbigou, C. Bruneau and P. H. Dixneuf, Chem Commun., 2002, 146-147.

7 It has been demonstrated that ruthenium alkylidenes with various $N$ heterocyclic carbene ligands are very active metathesis catalysts, too, $c f$ : (a) J. K. Huang, E. D. Stevens, S. P. Nolan and J. L. Petersen, J. Am. Chem. Soc., 1999, 121, 2674-2678; (b) M. Scholl, T. M. Trnka, J. P. Morgan and R. H. Grubbs, Tetrahedron Lett., 1999, 40, 2247-2250; (c) T. Weskamp, W. C. Schattenmann, M. Spiegler and W. A. Herrmann, Angew. Chem., 1998, 110, 2631-2633 (Angew. Chem., Int. Ed. Engl., 1998, 37, 2490-2493)

8 W. A. Herrmann and C. W. Kohlpaintner, Angew. Chem., 1993, 105, 1588-1609 (Angew. Chem., Int. Ed. Engl., 1993, 32, 1524-1544).

9 (a) E. A. Fehnel, J. Am. Chem. Soc., 1952, 74, 1569-1574; (b) E. A. Fehnel and P. A. Lackey, J. Am. Chem. Soc., 1951, 73, 2473-2479; (c) E. A. Fehnel, J. Am. Chem. Soc., 1948, 70, 1813-1817.

10 E. Vedejs, D. A. Engler and M. J. Mullins, J. Org. Chem., 1977, 42, 3109-3113. 